\title{
Socio-Economic Aspects in Satisfying Energy Demands by Different Technologies of Heat and Electricity Generation
}

\author{
Dinko ĐURĐEVIĆ, Dražen BALIĆ, Željko JURIĆ
}

\begin{abstract}
Results of the research on how different generation plants can satisfy heat demands and at the same time minimise operation costs, carbon dioxide $\left(\mathrm{CO}_{2}\right)$ emission and consumption of primary energy are presented in the paper. In that sense hierarchical optimization procedure was carried out which enables application of different criteria, i.e. it was possible to set different goal functions. Special attention was put on the $\mathrm{CO}_{2}$ emissions. In order to quantify the social impact of different generation plants, $\mathrm{CO}_{2}$ emission cost was analysed in different scenarios. Moreover, economic analysis was based not only on operation expenditures but also on the capital investments Different technologies were analysed, biomass-based cogenerations (wastewater sludge), fossil fuel-based cogenerations (in combination with gas engine and gas turbine), heat pumps, electric boilers and fossil fuel boilers. In order to determine optimal generation set-up simulation was carried out for a case of the City of Zagreb, Croatia. The simulation period was one year. It is shown that it is yet possible to achieve significant benefits with appropriate selection of generation mix, particularly in the $\mathrm{context}$ of $\mathrm{CO}_{2}$ reduction. Heat pumps together with biomass-based cogeneration technologies have shown the best potential for their utilisation in future energy system.
\end{abstract}

Keywords: $\mathrm{CO}_{2}$ emission; multi-criteria optimisation; social impact; techno-economic analysis; wastewater sludge

\section{INTRODUCTION}

Selection of optimal generation set-up, i.e. the most convenient technologies to satisfy thermal and electrical loads is becoming very complex. Reasons for that come from the appearance of new circumstances on the energy markets. Namely, implementation of European Union (EU) policies which have intention to combat the climate change through increase of renewable energy sources (RES) share, reduction of greenhouse gas emissions and increase of energy efficiency in many sectors [1], caused fundamental changes on energy markets. Conventional power plants, such as large-scale coal-, oil- or even gasfired plants, become uncompetitive on the more and more dynamic power markets. Such power plants do not have the technical ability to adapt to the changing circumstances and therefore their load factor, i.e. number of operational hours throughout the year decreases and opportunity costs are inevitable. Possible options for these plants are adoption of advanced operation strategies and/or reduction of minimal technical load, for instance.

According to ENTSO-E study [2], share of RES increased by $4.9 \%$ from 2013 to 2014 , with parallel decrease of electricity consumption of $2.4 \%$ in the same period. Ambitious goals of the EU regarding the share of RES in total energy mix in 2030 and 2050 impose certain challenges that need to be overcome. In order to achieve desired shares of RES it is necessary to undergo an energy transition. The energy transition implies the process where energy demands must be satisfied with both RES and conventional sources. This could be done by utilization of waste as an energy source, e.g. wastewater sludge, which has a relatively high calorific value [3]. However, conventional sources should make certain improvements to satisfy rigorous technical requirements, mainly in the sense of carbon dioxide $\left(\mathrm{CO}_{2}\right)$ emission, flexible operation strategies, low operational and capital expenditures, in order to stay operational and competitive on the market.

By literature review, it is noticeable that many authors recognized, such problems within the energy sector. Some of them put emphasis on the legal, i.e. regulatory framework, while part of them on technical matters related mainly on the optimization problems, in order to minimise operational cost of certain generation set-up.

Späth and Rohracher [4] deal with so called sustainability transitions. It was identified that process of energy sector transformation has already undergone in the city of Freiburg, Germany, without adequate preparation, as an answer to a need to make long term decisions, regarding the reduction of environmental impact of space heating. The idea was to reduce social impact as well as costs via implantation of district heating or through improvements of buildings envelops and thus to reduce energy needs. Another example of the transition in urban area is given by Webb [5], where techno-economic assessment of the district heating systems in Scotland was presented. It was shown that it is possible to achieve significant $\mathrm{CO}_{2}$ emission reduction $(45 \%$ compared to electric heating) if the adequate framework is developed. Carbon savings are possible to be achieved if fuel, such as biomass (e.g. biomass waste, such as wastewater sludge), is utilised. Santoli et al. [6] introduced a Zero-kilometre Energy model where biomass is locally available and thus transportation does not impose additional costs and $\mathrm{CO}_{2}$ emissions. Authors highlighted the potential savings in $\mathrm{CO}_{2}$ emission when different kinds of biomass were utilised.

Lund and Mathiesen [7] analysed the impact of higher share of intermittent RES on the stability of Danish power system. They used the term of "smart energy system" to emphasize the importance of integration of the cogeneration power plants coupled with the district heating system with RES, in order to reduce socio-economic cost and consumption of scarce biomass. It was concluded that combined cycle gas turbine (CCGT) plant is the most suitable in technical and economic context. Again, it was concluded that present regulatory and economic framework does not give adequate support to develop large scale cogeneration power plants. Similar findings were presented by Connolly et al. [8] where authors analysed the impact of the transition to the $100 \%$ renewable energy system on the primary energy consumption, $\mathrm{CO}_{2}$ emissions and total annual socio-economic cost. They proposed an integration of various sectors, such as electricity, heating, 
cooling and transportation where certain amount of flexibility could be procured as well. Such transition, according to authors, would be $10-15 \%$ more expensive than business-as-usual (BAU) scenario. However, they concluded that additional 10 million of direct jobs within the EU would be generated.

Social and institutional dimensions of energy distribution networks were addressed by Bolton and Foxon [9], together with a need of appropriate governance in order to develop more flexible and sustainable system which would have key role for a low carbon transition. Moreover, Lund et al. [10] go even further and introduce concept of smart energy grids with basic assumption that the district heating and cooling systems must be further developed in order to provide support to the future energy system which integrates a high share of RES.

Similar to the ideas of integration of different energy sectors some authors support idea of polygeneration together with the process integration $[11,12]$. With such approach, natural resources are better utilised, positive impact on the socio-economic development of societies is achieved together with an increase in energy efficiency. Moreover, very often is the question on which level (e.g. city, community, building) such integration of processes will have the best possible outcome.

However, in order to achieve best possible outcomes in the sense of reduction of costs, $\mathrm{CO}_{2}$ emission and primary energy consumption, it is necessary to deploy various optimization procedures and methods. By literature review, it is possible to notice that there are many approaches regarding the processes which are being optimized and optimization procedures being applied. Truong and Gustavsson [13] showed that the goal function was to minimise the cost of the district heating system depending on a size of the production plant. The different cogeneration plants as well as stand-alone generation facilities were considered. Fang and Lahdelm [14] developed an optimal operation strategy for heat generation plants. They used available data from a smart metering system which gave them spatially and temporally more accurate information thus enabling reduction of pumping and fuel costs of one or more generation plants. When generation plants are considered, it is necessary to determine the optimal share of cogeneration plants versus stand-alone heat generation plants. The mentioned share implicates different operation and social costs which have certain impact on the society and thus should not be neglected when longterm decisions are made [15]. Due to the more and more dynamic energy markets, new participants emerge on the markets - energy storage. Energy storage becomes very important when the stability of the power and heat systems is considered. Namely, intermittent RES (mostly wind and photovoltaics) have favoured position on the market in a way they have dispatched priority and feed-in tariffs - rights given by energy regulators. In that sense energy storage can significantly contribute when stabilisation of the system is in question. Wang et al. [16] and Nuytten et al. [17] presented benefits of energy storage coupled with the cogeneration plants and district heating systems. Energy storage can provide flexibility at the demand side and therefore they have a crucial role when optimization of generation plants is carried out. Pini Prato et al. [18] put emphasis on modelling transient phenomena when optimization of cogeneration power plant coupled with district heating was being conducted, while Chicco and Mancarella [19] give comprehensive input-output matrix approach for modelling and optimization of cogeneration and trigeneration systems. Multi-criteria optimization procedure was given in [20], when different goal functions were applied hierarchically in order to optimise small scale trigeneration system.

Various research has been conducted to obtain the optimal solution for energy and heat generation, with minimum environmental impact goal. In mentioned researches it is shown how the optimal solution is obtained through utilization of RES system coupled with present systems. From socio-economic point of view, it is a great solution, considering the fact that existing power plants will not require additional expensive and extensive upgrades.

Following the mentioned approach, this paper considers the optimization of a small scale system through multi-criteria optimization procedure.

\section{MATERIALS AND METHODS}

The research presented within this paper has in focus to explore various commercially available technologies for heat and electricity generation (cogeneration technologies) and to determine the optimal one for the given boundary conditions. The technologies taken into consideration are the following: combined cycle gas turbine (CCGT), gas engine (GE), combined cycle gas turbine propelled by the gas from the biomass gasification process (BCCGT), gas engine propelled by the gas from biomass gasification process (BGE), gas boiler (GB), electric boiler (EB) and electricity driven heat pumps (HP). Previously mentioned boundary conditions comprise as follows: heat demand, price of electricity, price of natural gas, price of biomass (in this case wastewater sludge from wastewater treatment plants, due to the fact that majority of sludge is of organic, biomass, origin), and price of $\mathrm{CO}_{2}$ emission.

The whole research can be divided into two parts. The first one addresses the price of generated heat from various heat sources. However, the calculation of the heat price was based not only on operational expenditures, but also on capital, i.e. investment costs. The idea was to explore how different parameters, such as number of operational hours, price of electricity, gas, wastewater sludge and $\mathrm{CO}_{2}$ emission influence the cost of generated heat and which technology is thereby the most appropriate, in given circumstances. In the second part of the research multicriteria optimization procedure was developed,with the intention to determine the optimal generation set-up. The simulation was based on the data from EL-TO cogeneration power plant in the City of Zagreb on the hourly basis for the year 2012, due to the fact that all necessary data were available for the selected year.

Within the research the following assumptions were introduced:

- To calculate the price of generated heat from the cogeneration technologies (CCGT, GE, BCCGT, $\mathrm{BGE}$ ) the price of generated electricity was considered as the average annual price on the Hungarian Power Exchange (HUPX) for the year 2012 (HUPX was used 
because Croatian Power Exchange (CROPEX) was established in 2014)

- To calculate the price of generated heat from the technologies which use electricity for heat generation (EB and HP), the price of the electricity was again considered as the average annual price on the Hungarian Power Exchange for the year 2012

- $\quad$ For the purposes of the simulation, prices of electricity were being changed on an hourly basis for the year 2012. The prices of electricity were based on the historic data prices from HUPX for the year 2012

- $\quad$ For the purpose of simulation, prices of natural gas were fixed

- Since wastewater management in Croatia is still in its early phase and sludge as a product does not have a determined price on the market, the price of wastewater sludge (dried and pelletized) was considered as constant throughout the year and the same value was used for both calculation of the price of generated heat and for the simulation.

- Expected lifetime of all technologies was 25 years (expected lifetime of some technologies is shorter, however, the case in Croatia is that many technologies have a prolonged lifetime, due to impossibility for replacement) [21, 22, 23]

- $\quad$ Discount rate was set to the value of $8 \%$

- Primary energy factors and $\mathrm{CO}_{2}$ emissions for natural gas, electricity from the grid and wastewater sludge are given in Tab. 1

- $\quad$ According to [24] price of $\mathrm{CO}_{2}$ emission in 2012, 2030 and 2050 amounts to $10 \mathrm{EUR} / \mathrm{tCO}_{2}, 35 \mathrm{EUR} / \mathrm{tCO}_{2}$ and $100 \mathrm{EUR} / \mathrm{tCO}_{2}$, respectively

Table 1 Primary energy factors and $\mathrm{CO}_{2}$ emissions [25, 26, 27]

\begin{tabular}{|c|c|c|}
\hline Fuel & Primary energy factor & $\mathrm{CO}_{2}$ emission \\
\hline & - & $\mathrm{t}^{\mathrm{MWh}}$ fuel \\
\hline Natural gas & 1.097 & 0.2202 \\
\hline Electricity from the grid & 1.614 & 0.2348 \\
\hline Wastewater sludge & 0 & 0.1868 \\
\hline
\end{tabular}

\subsection{Cost of Generated Heat}

As it was previously mentioned, the price of heat generated by the different technologies was determined not only on the operational, but also on the investment expenditures. The operational expenditures comprised of variable cost for operation and maintenance depending on the number of hours certain technology is deployed and of the fixed costs for operation and maintenance. The investment costs were discounted for the period of the lifetime according to the chosen discount rate. Apart from the mentioned costs, cost of the generated heat depends on the costs for the fuel and for the emission of $\mathrm{CO}_{2}$. In this paper, four prices of $\mathrm{CO}_{2}$ emission were considered. The formula for the cost calculation of generated heat from the $i^{\text {th }}$ unit is taken from [16] and adapted to the following equation:

$$
\begin{aligned}
& C_{\text {heat }, i}=\frac{C_{\text {fuel }, i}+C_{\mathrm{CO}_{2}, i}+C_{\mathrm{VOM}, i}}{\eta_{\mathrm{h}, i}} C_{\text {el. }} \cdot P t H_{i}+ \\
& +\frac{C R F \cdot C_{\mathrm{Cap}, i}+C_{\mathrm{FOM}, i}}{t}
\end{aligned}
$$

where $C_{\mathrm{fuel}, i}, C_{\mathrm{CO} 2, i}, C_{\mathrm{VOM}, i}, C_{\mathrm{Cap}, i}, C_{\mathrm{FOM}, i}$ stand for the cost of fuel, cost of $\mathrm{CO}_{2}$ emission, variable cost of operation and maintenance, investment cost and fixed cost of operation and maintenance for the $i$-th unit, respectively. $\mathrm{PtH}_{i}$ is a power-to-heat ratio of the $i$-th unit, $C_{\text {el. }}$ is the cost of electricity, $C R F$ is capital recovery factor while the $\eta_{\mathrm{h}, i}$ is the thermal efficiency of the $i$-th unit. If the cost of heat is considered for heat-only plants, then $\mathrm{PtH}$ equals zero. $t$ denotes the number of hours the $i$-th unit is deployed throughout the year, while $i$ represents one of the heat generation technologies (CCGT, GE, BCCGT, BGE, HP, $\mathrm{EB}, \mathrm{GB})$

For the purpose of this research, $\eta_{\mathrm{h}, i}$ equals the coefficient of performance (COP) when the heat pumps are considered. COP will be described in more detail in the following chapters.

\subsection{Multi-Criteria Optimisation Procedure}

In order to determine optimal technology for heat generation, multi-criteria optimization procedure was developed. Namely, three different criteria were applied hierarchically, in order to obtain optimal solution. The criteria were the following: minimal cost, minimal emission of $\mathrm{CO}_{2}$ and minimal consumption of primary energy. The system consisted always of the HP, EB and $\mathrm{GB}$ and one of the mentioned cogeneration technologies (CCGT, GE, BCCGT or BGE). For each case, i.e. for each cogeneration technology optimization procedure was carried out where aforementioned criteria were applied in order to minimise operational costs, $\mathrm{CO}_{2}$ emission and primary energy consumption. After the optimal operation strategy for the certain cogeneration technology (case) was determined, for each hour throughout the year, it was possible to integrate results and to conclude which technology is the most suitable, i.e. optimal on yearly basis. Certain cogeneration technology was always compared with the electric and gas boiler and with the heat pump, as it is shown in Fig. 1.

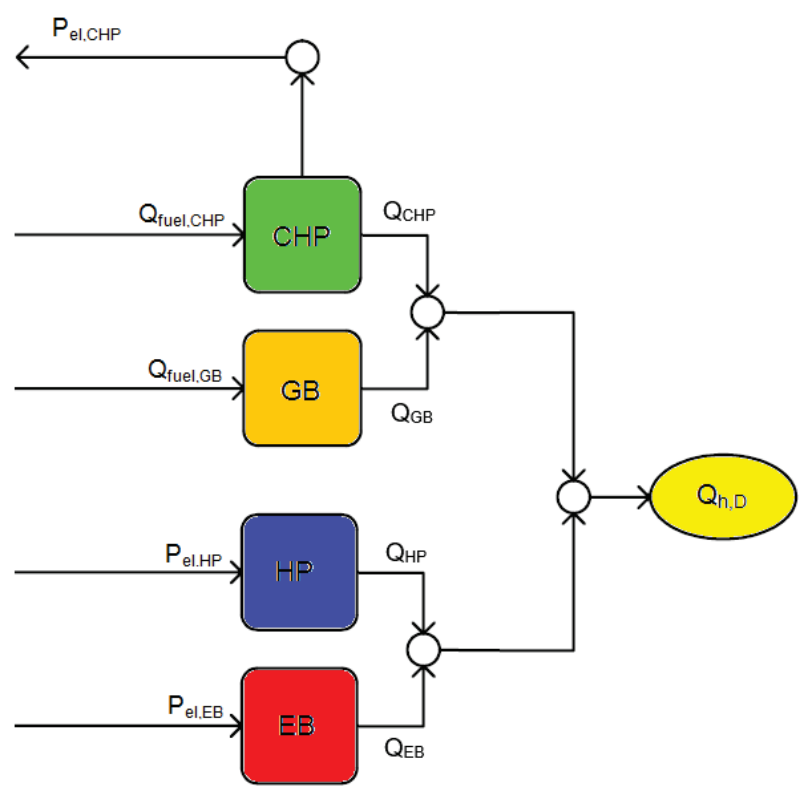

Figure 1 Scheme of the analysed system. CHP refers to CCGT, GE, BCCGT or BGE - depending on the simulation case 
This set-up was chosen because it is non-realistic that one site contains all mentioned technologies installed, due to their competition which would be present throughout the year. Hence, there were four cases and for each of them the optimization procedure was carried out. The following cases were analysed:

$\begin{array}{lll}\text { 1. } & \text { CCGT } & \text { HP EB GB } \\ \text { 2. } & \text { GE } & \text { HP EB GB } \\ \text { 3. } & \text { BCCGT } & \text { HP EB GB } \\ \text { 4. } & \text { BGE } & \text { HP EB GB }\end{array}$

Concerning the optimization algorithm, for each observed hour, heat demand as well as electricity, gas, and wood chip price were known. As it can be noticed from Fig. 1 , the system has three degrees of freedom. This means that, if the load of any three technologies is known, the load of the remaining fourth technology is unambiguously determined. In that sense it was necessary to simultaneously vary load of any three technologies and to calculate operational cost, $\mathrm{CO}_{2}$ emission and primary energy consumption. Due to the fact that optimization procedure was based on three criteria, the algorithm consists of the three main parts i.e. stages. First part is focused on finding a set of solutions with operational costs below a given threshold for analysed hour by varying the loads of the generation technologies. This set of solutions represented input for the second stage i.e. second part, where second criterion was applied and from the input set of solutions only the ones with $\mathrm{CO}_{2}$ emission below the given threshold were extracted. This was achieved by deployment of second criterion, i.e. second goal function for minimising the $\mathrm{CO}_{2}$ emission. The results of the second stage of optimization procedure was the set of solutions for the observed hour which reflected possible solutions, i.e. operational strategies with minimal costs and minimal $\mathrm{CO}_{2}$ emission. The output of the second stage was input for the third and final stage of optimization procedure where final criterion was applied by the means of goal function for finding minimal consumption of primary energy. The solution given by the third stage of optimization procedure for the observed hour was the optimal solution, i.e. optimal operation strategy which ensures generation of required amount of heat by cogeneration technology (which was being observed), HP, EB and GB. The described procedure was applied for 8,760 hours of year 2012 for the known load of the City of Zagreb. The flowchart of optimization procedure is shown in Fig. 2.

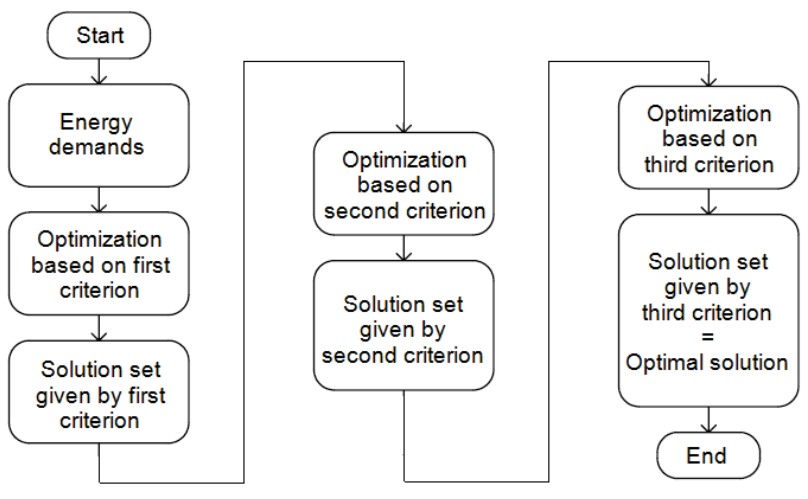

Figure 2 Optimization method flowchart

\subsubsection{Formulation of Goal Functions}

The first stage of optimization procedure has in focus the derivation of set of optimal solutions based on the goal function for minimal cost, as it is shown by Eq. (2).

$$
\begin{aligned}
& C_{\mathrm{opt}}^{z}=\min \left\{Q_{\text {fuel, } \mathrm{CHP}}^{z} \cdot C_{\text {fuel, } \mathrm{CHP}}^{z}+Q_{\text {fuel }, \mathrm{GB}}^{z} \cdot C_{\text {fuel }, \mathrm{GB}}^{z}+\right. \\
& \left.+\left(P_{\mathrm{el} . \mathrm{HP}}^{z}+P_{\mathrm{el} . \mathrm{EB}}^{z}-P_{\mathrm{el}, \mathrm{CHP}}^{z}\right) \cdot C_{\mathrm{el} .}^{z}\right\}
\end{aligned}
$$

Where $C_{\mathrm{opt}}^{z}, \quad C_{\text {fuel,CHP }}^{z}, \quad C_{\text {fuel,GB }}^{z}$ and $C_{\mathrm{el}}^{z}$ represent minimal cost of operation of generation set-up, cost of fuel for chosen cogeneration technology, cost of fuel for gas boiler and price of electricity during the $z$-th hour $(z \in[1,8,760] \subset N)$, respectively. $Q_{\text {fuel,CHP }}^{z}$ and $Q_{\text {fuel,GB }}^{z}$ stand for consumption of fuel for the chosen cogeneration technology and the gas boiler during the $z$-th hour, respectively, while $P_{\mathrm{el} ., \mathrm{HP}}^{z}, P_{\mathrm{el} . \mathrm{EB}}^{z}$ and $P_{\mathrm{el} ., \mathrm{CHP}}^{z}$ represent consumption of electricity of the heat pump and the electric boiler as well as generation of electricity by the chosen cogeneration technology during the $z$-th hour.

Second stage of optimization procedure was dedicated to extract the possible operation strategies, for given hour, where $\mathrm{CO}_{2}$ emissions are the lowest. The goal function of the second criterion is formulated as follows:

$$
\begin{aligned}
& C E_{\mathrm{opt}}^{z}=\min \left\{Q_{\text {fuel, } \mathrm{CHP}}^{z} \cdot C E_{\text {fuel, } \mathrm{CHP}}+Q_{\text {fuel, } \mathrm{GB}}^{z} \cdot C E_{\mathrm{gas}}+\right. \\
& \left.+\left(P_{\mathrm{el} ., \mathrm{HP}}^{z}+P_{\mathrm{el} ., \mathrm{EB}}^{z}\right) \cdot C E_{\mathrm{el} .}\right\}
\end{aligned}
$$

where $C E_{\text {opt }}^{z}$ represents the minimal $\mathrm{CO}_{2}$ emission for the $z$-th hours, while $C E_{\text {fuel,CHP, }} C E_{\text {gas }}$ and $C E_{\text {el. }}$ stand for the amount of $\mathrm{CO}_{2}$ emission per MWh of utilised fuel for cogeneration technology, natural gas and electricity from the grid, respectively.

Third and final goal function is to find the operation strategy for the given hour where utilisation of primary energy is minimal. The formulation of the goal function is given by Eq. (4).

$$
\begin{aligned}
& P E U_{\mathrm{opt}}^{z}=\min \left\{Q_{\text {fuel, } \mathrm{CHP}}^{z} \cdot P E F_{\text {fuel, } \mathrm{CHP}}+Q_{\text {fuel, } \mathrm{GB}}^{z} \cdot P E F_{\mathrm{gas}}+\right. \\
& \left.+\left(P_{\mathrm{el} . \mathrm{HP}}^{z}+P_{\mathrm{el} . \mathrm{EB}}^{z}\right) \cdot P E F_{\mathrm{el} .}\right\}
\end{aligned}
$$

$P E U_{\mathrm{opt}}^{z}$ represents the minimal consumption of primary energy in the $z$-th hour for the given operation strategy of the observed generation set-up (case). $P E F_{\text {fuel,CHP, }} P E F_{\text {gas }}$ and $P E F_{\text {el. }}$ stand for primary energy factors for the fuel of the chosen cogeneration technology, natural gas and electricity from the grid, respectively.

\subsection{Techno-economic Characteristics of the Generation Technologies}

Tab. 2 summarizes main technical as well as economic characteristics of the generation technologies which were used for the purposes of the optimization procedure as well as to determine the cost of heat. 
As it was mentioned, in each case heat pump was available technology which competes with certain cogeneration technology, GB and EB, in order to satisfy heat demand in the observed hour. However, efficiency of heat pump is highly dependent on the operation conditions, i.e. on the enthalpy content of the heat source and heat sink. In the periods when heat demand is low, and the temperatures of the supply water are lower, efficiency of the heat pump is significantly greater compared with the periods of high heat demand when the supply water temperature is also high. The efficiency of the heat pump is described with the quantity of COP. Due to the fact that supply water temperatures in district heating system can achieve relatively high values (cca $90{ }^{\circ} \mathrm{C}$ ) it was necessary to calculate the COP which depends on the supply water temperature. In this paper, COP was determined for twostage heat pump. The dependence of COP upon temperature of supply water is given in Fig. 3 .

Table 2 Characteristics of generation technologies derived from $[17,28,29]$

\begin{tabular}{|c|c|c|c|c|c|c|}
\hline \multirow{2}{*}{ Technology } & $\eta_{\mathrm{h}}$ & $\eta_{\mathrm{e}}$ & $\mathrm{PtH}$ & $C_{\mathrm{Cap}}$ & $C_{\mathrm{FOM}}$ & $C_{\mathrm{VOM}}$ \\
\hline & $\%$ & $\%$ & - & EUR/MW ${ }_{\text {heat }}$ & EUR/MW ${ }_{\text {heat }} / \mathrm{y}$ & EUR/MWh ${ }_{\text {fuel }}$ \\
\hline CCGT & 41.5 & 50.5 & 1.217 & $1,300,000$ & 27,000 & 0.90 \\
\hline GE & 40.0 & 48.0 & 1.200 & 600,000 & 40,000 & 2.00 \\
\hline BCCGT & 51.0 & 37.0 & 0.725 & $2,500,000$ & 55,000 & 4.00 \\
\hline BGE & 48.0 & 42.0 & 0.875 & $2,700,000$ & 67,000 & 4.20 \\
\hline GB & 90.0 & - & - & 180,000 & 2,800 & 0.70 \\
\hline EB & 99.5 & - & - & 22,299 & 2,000 & 0.50 \\
\hline $\mathrm{HP}(\mathrm{COP}=2.1)$ & 210.0 & - & - & 400,000 & 3,000 & 0.20 \\
\hline $\mathrm{HP}(\mathrm{COP}=3.5)$ & 350.0 & - & - & 400,000 & 3,700 & 0.20 \\
\hline
\end{tabular}

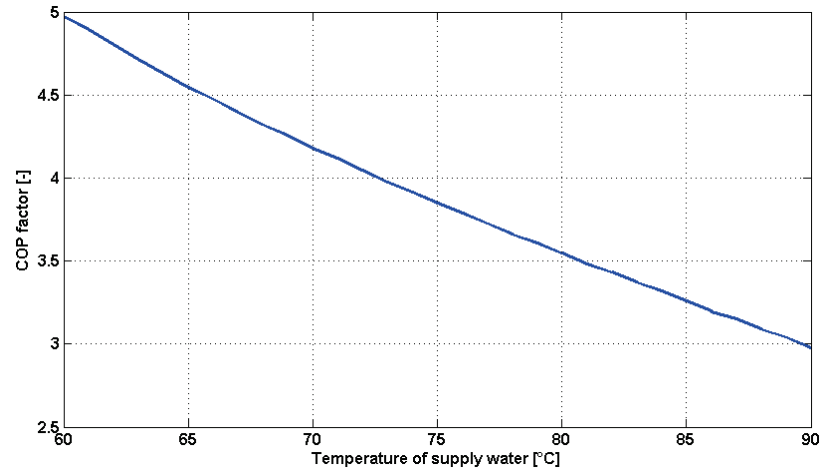

Figure 3 Impact of the supply water temperature on the COP factor of heat pump

During the simulation, COP factor was changed for each hour in simulation depending on the supply water temperature.

\subsection{Input Data for Simulation}

To obtain optimization procedures and to compare cogeneration technologies, simulation was carried out for the City of Zagreb for the year 2012. The known data were heat demand in each hour throughout the year. The historic price data of electricity for the year 2012 was taken from the HUPX on the hourly basis (HUPX 2012) [30]. Price of natural gas was changed on the monthly basis. Wastewater sludge is mostly pelletized for utilization in agriculture and has a higher cost of around $85 \mathrm{EUR} / \mathrm{MWh}$ [31, 32]. However, for the purpose of this paper, the price of pelletized wastewater sludge is set to a constant value of $30 \mathrm{EUR} / \mathrm{MWh}$, due to the fact that it only requires drying and pelletizing, without any additions usually necessary for utilization on agricultural fields (e.g. hygienisation).

Due to the fact that maximal heat demand at EL-TO power plant in the City of Zagreb in 2012 was $323 \mathrm{MW}$, the heat capacities of the observed technologies were set to the following maximal values:

- $\quad \mathrm{CHP}-200 \mathrm{MW}$

- $\quad \mathrm{HP}-200 \mathrm{MW}$

- $\mathrm{GB}-80 \mathrm{MW}$
Heat capacity of the electric boiler was not limited, and it could theoretically satisfy an unlimited heat demand.

Fig. 4 shows load duration curve of heat demands which were satisfied by EL-TO cogeneration power plant in the year 2012. These data were the base for applying optimization procedure.

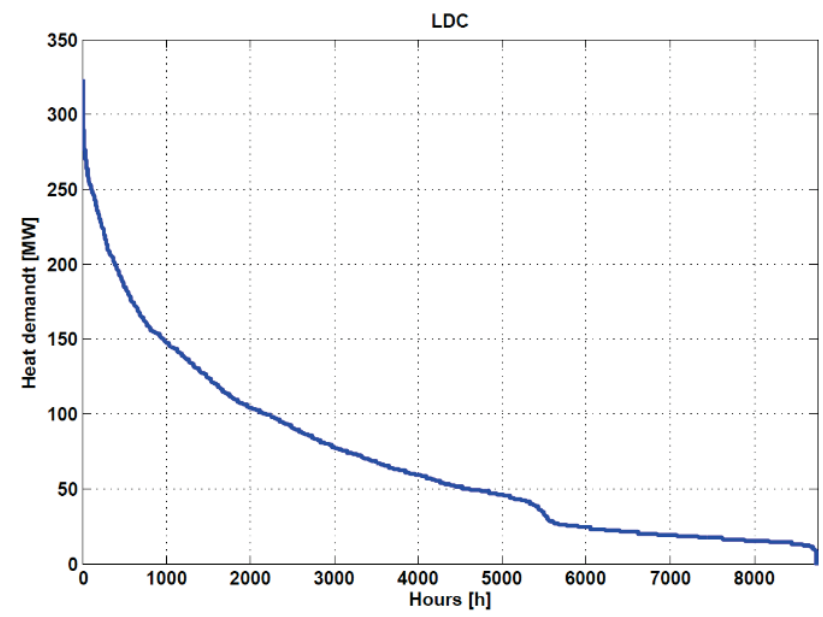

Figure 4 Load duration curve of EL-TO power plant for Zagreb in 2012

\section{RESULTS}

\subsection{Analysis of Generated Heat Cost}

The price of generated heat by the one of the observed technologies was determined, not only on the operational expenditures but, also by taking into account discounted value of the investment costs and the price of $\mathrm{CO}_{2}$ emission. Due to the fact that expected lifetime of the observed technologies is approximately 25 years, different prices of $\mathrm{CO}_{2}$ emissions were observed, from $10 \mathrm{EUR} / \mathrm{tCO}_{2}$ in 2012 (EUR value approximated to value from 2010) to $35 \mathrm{EUR} / \mathrm{tCO}_{2}$ in 2030 and an ultimate case of $100 \mathrm{EUR} / \mathrm{tCO}_{2}$ which is expected in 2050, according to [24]. In that sense the price of generated heat was analysed for the cases of $0,10,35$ and $100 \mathrm{EUR} / \mathrm{tCO}_{2}$ and the results are shown in Figs. 5-8, respectively. 
Cost of heat without $\mathrm{CO}_{2}$ cost

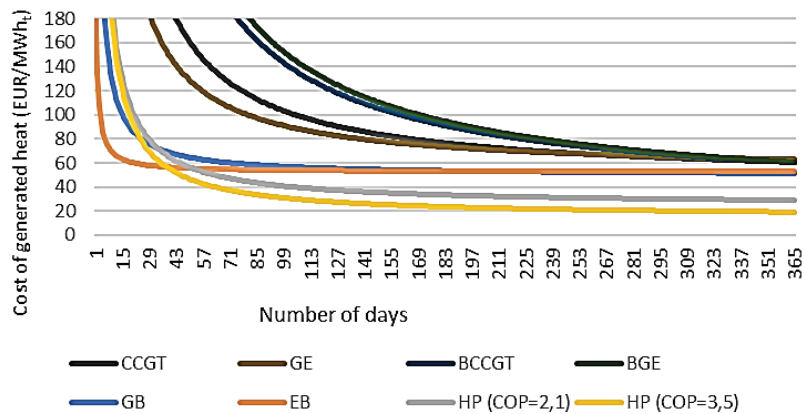

Figure 5 Cost of generated heat in the case of $\mathrm{CO}_{2}$ emission price of 0 $\mathrm{EUR} / \mathrm{tCO} 2$

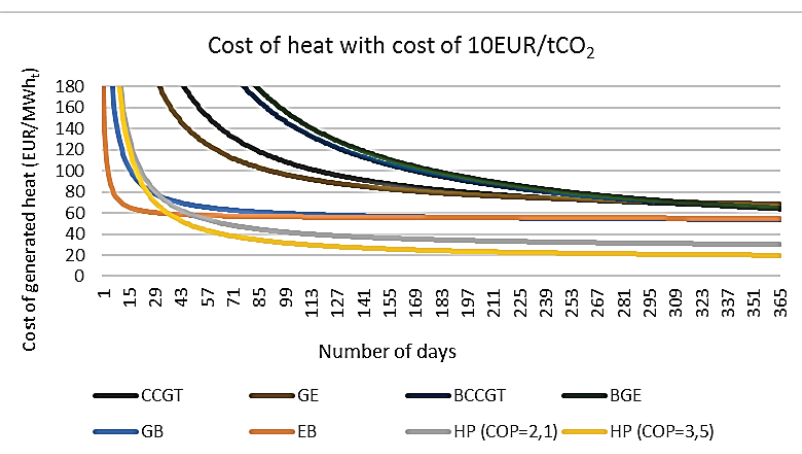

Figure 6 Cost of generated heat in the case of $\mathrm{CO}_{2}$ emission price of 10 $\mathrm{EUR} / \mathrm{tCO}_{2}$

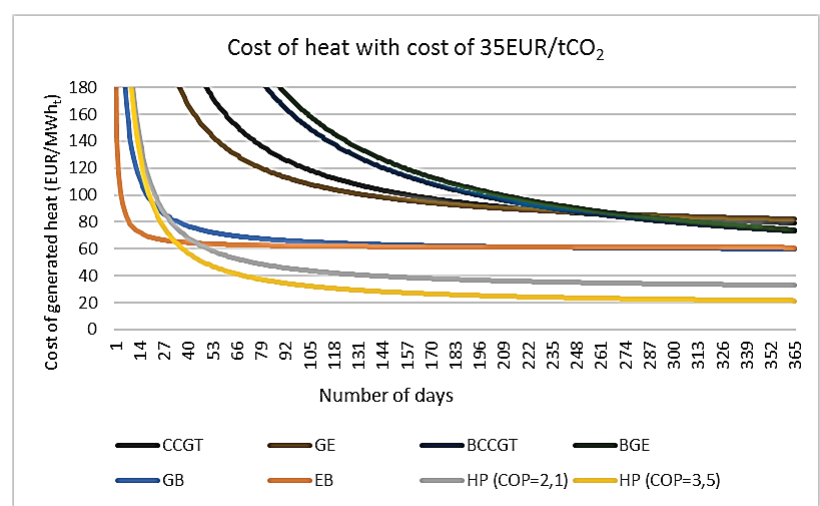

Figure 7 Cost of generated heat in the case of $\mathrm{CO}_{2}$ emission price of 35 EUR/tCO2

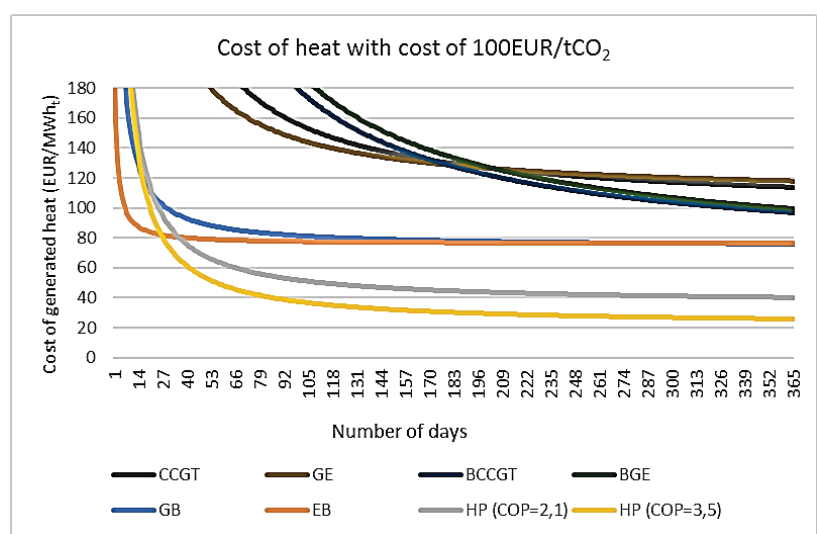

Figure 8 Cost of generated heat in the case of $\mathrm{CO}_{2}$ emission price of 100 $\mathrm{EUR} / \mathrm{tCO}_{2}$

It can be noticed that increase of $\mathrm{CO}_{2}$ price has the smallest impact on the cost of heat generated by the HPs and biomass-based technologies. The reasons for that should be sought in the fact that HPs have a low specific investment costs, high efficiency and low associated $\mathrm{CO}_{2}$ emissions, while the biomass-based technologies emit the smallest amounts of $\mathrm{CO}_{2}$ per MWh of generated heat. GB and $\mathrm{EB}$ are specific in the sense of a payback period. Namely, it is sufficient that they operate more than cca 100 days per year and the price of produced heat will be between 50 and $80 \mathrm{EUR} / \mathrm{MWh}$, depending on the price of $\mathrm{CO}_{2}$ emission. On the other hand, CCGT and GE require the largest number of operating hours throughout the year, in order to achieve lower price of the generated heat.

Another interesting fact is the situation where the price of generated heat is almost the same for the natural gasbased cogeneration technologies (CCGT and GE) as well as for biomass-based cogeneration technologies (BCCGT and BGE) and heat-only technologies (EB and GB), at approximately 260 days of operation.

From all analysed cases it can be concluded that CCGT and GE produce the heat at the greatest cost which implicates, in the economic sense, that such technologies from this point of view are not economically appealing, although their advantages, such as flexible response (ancillary services), are crucial when stability maintaining of the power system is in question. In order to evaluate those benefits, a model of electricity market, i.e. market of ancillary services, should be included.

Another analysis carried out within this research was to derive comprehensive overview of the most adequate, i.e. economically optimal technology, for the given prices of heat, electricity and $\mathrm{CO}_{2}$ emissions. The impact of the electricity to gas price ratio and the price of $\mathrm{CO}_{2}$ emission on the most suitable generation technology is shown in Figs. 9-11 for the 150, 225 and 350 days of operation throughout the year, respectively. In the analysis HP and biomass-based technologies (BCCGT and BGE) were not considered. Namely, from Figs. 5-8 it can be seen that heat pumps produce heat at the lowest cost, even when the COP is low $(\mathrm{COP}=2.1)$. Similar situation is with the biomassbased technologies where the heat price amounts to values similar to those of heat pumps.

If the number of operation hours, i.e. days is relatively small then EB and GE should be considered. Expectedly, $\mathrm{EB}$ is more appropriate technology if the electricity price is lower and vice versa for GE. Increase in $\mathrm{CO}_{2}$ emission price is in favour of EB.

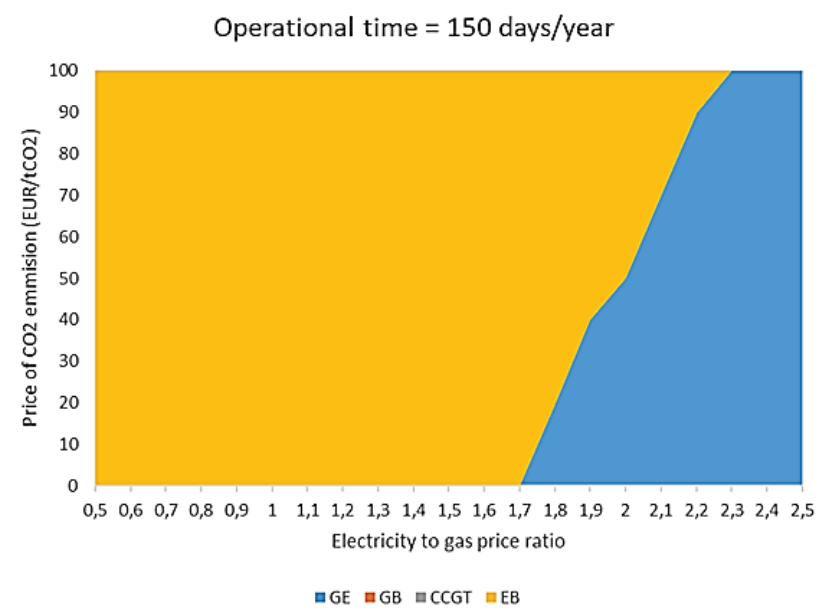

Figure 9 Impact of electricity, gas and $\mathrm{CO}_{2}$ emission price on the most adequate technology if 150 days in operation throughout the year 
Interesting situation is in the case of 225 days of operation. CCGT contributes to the heat generation in the cases of high electricity and $\mathrm{CO}_{2}$ emission prices, while in the case of relatively low electricity and $\mathrm{CO}_{2}$ emission price GB is the most promising technology. $\mathrm{EB}$ is the most convenient for cases of low electricity and high $\mathrm{CO}_{2}$ emission prices.

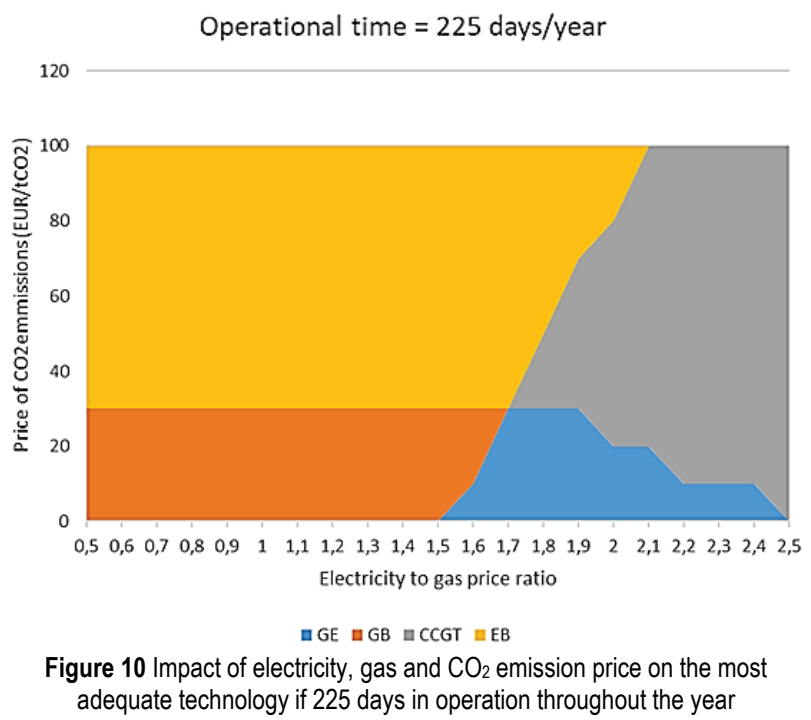

In the case of extremely high numbers of operational hours, gas is the optimal type of fuel. In the case of high electricity price CCGT is the most convenient technology, otherwise GB should be deployed.

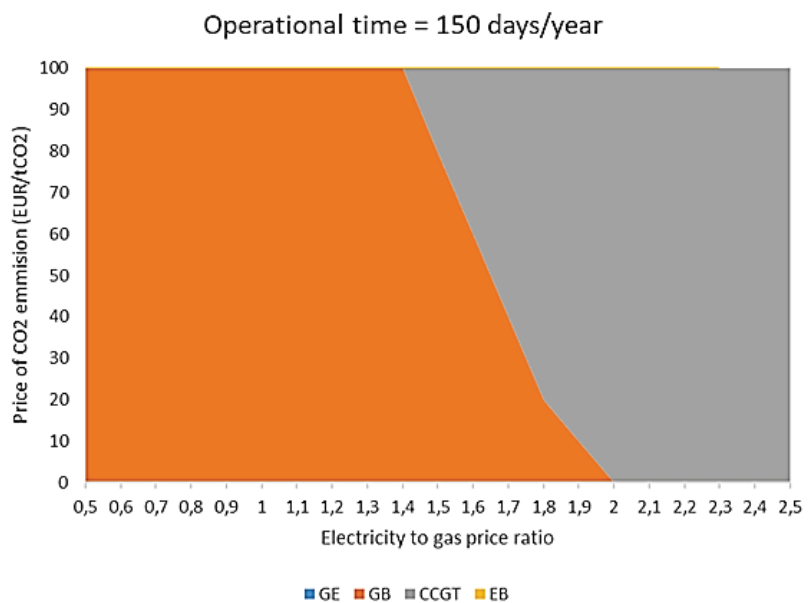

Figure 11 Impact of electricity, gas and $\mathrm{CO}_{2}$ emission price on the most adequate technology if 350 days in operation throughout the year

\subsection{Analysis of Optimal Generation Set Up for Heat Generation}

In the following figures results are presented regarding the optimization procedure for each of four observed cases for the City of Zagreb during the year 2012. Fig. 12 and Fig. 13 reflect optimal generation mix in the case of CCGT and GE as cogeneration technology, respectively. It can be noticed from both of figures that HP as well as EB satisfy most of heat demand throughout the year, while cogeneration and GB participate in smaller amount. In other words, it can be concluded that electricity is more favourable than gas as a fuel for heat generation.

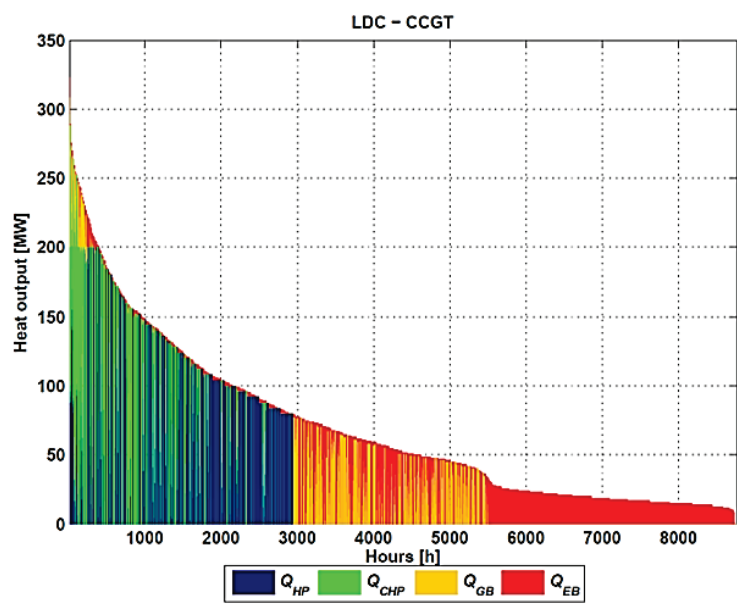

Figure 12 Load duration curve for CCGT case

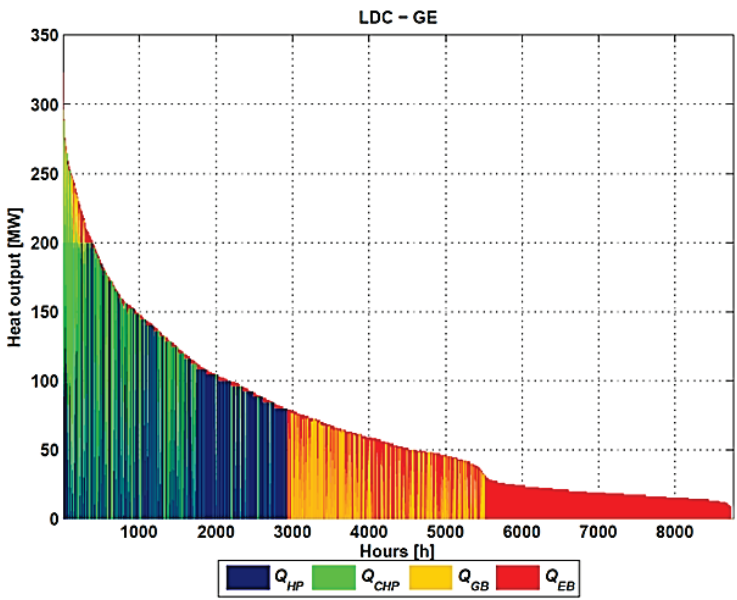

Figure 13 Load duration curve for GE case

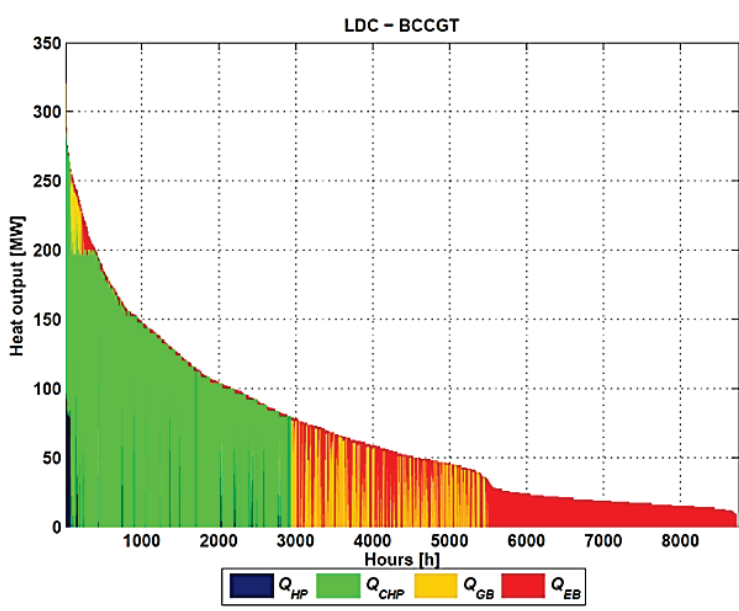

Figure 14 Load duration curve for BCCGT case

In the case of wastewater sludge as a fuel for the cogeneration technologies, the situation is slightly different. Biomass-based cogenerations satisfy approximately $60 \%$ of the yearly heat demands, where EB is the second most deployed generation technology. The load duration curve for BCCGT and BGE with participation of certain technology in heat generation throughout the year is given in Fig. 14 and Fig. 15, respectively. 


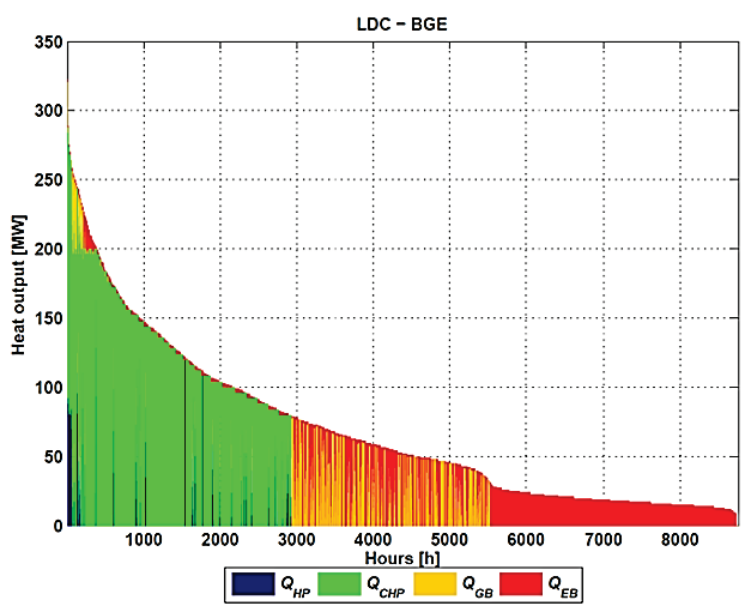

Figure 15 Load duration curve for BGE case

More comprehensive comparison of the four observed cases is given in Fig. 16, where shares in heat generation of observed technologies for each case is given. It can be distinguished that HP has a dominant role in the cases of cogeneration technologies propelled by a natural gas. In both cases, CCGT and GE, HP participated with approx. $50 \%$ in total heat generation. On the other hand, biomass-

Shares in generation - CCGT case

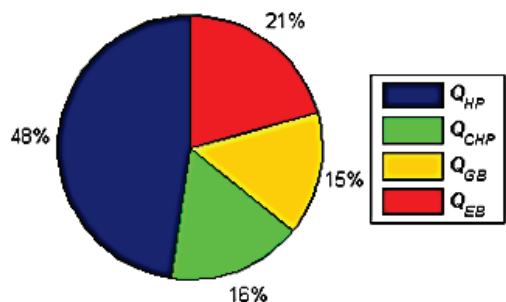

Total cost $=14341249$ EUR
Total $\mathrm{CO}_{2}$ emlssion=127 091

Total PE consumption=730 $027 \mathrm{MWh}$

Shares in generation - BCCGT case
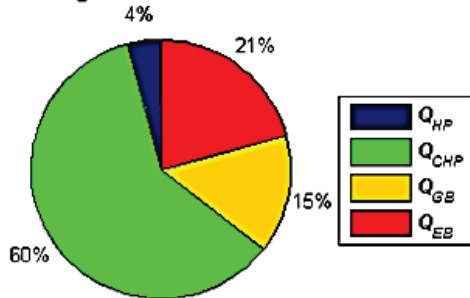

Total cost $=1858890$ EUR

Total PE consumption=1 $260243 \mathrm{MWh}$ based cogeneration technologies participated with approx. $60 \%$ in total heat generation. Reasons for that should be sought primarily in the relatively low price of wastewater sludge pellets, compared to gas and electricity and of course in low $\mathrm{CO}_{2}$ emission allocated to the biomass fuels. Another interesting fact is share of GB. In each case GB participates with $15 \%$, mostly during the peak hours.

Regarding the costs, the BCCGT case achieved the lowest cost, while GE was the most expensive case. However, the CCGT and GE have very similar total annual cost, while GE achieves better performances regarding $\mathrm{CO}_{2}$ emissions and consumption of primary energy. In the case of the biomass-based cogeneration technologies, BCCGT achieves lower cost compared to BGE, but when $\mathrm{CO}_{2}$ emission and primary energy consumption are in question, BGE gives better results. In the cases with cogeneration technology based on natural gas, main part of heat demands is satisfied with heat pump which has high thermal efficiency (COP) and therefore small consumption of primary energy. When biomass-based cogeneration technologies are in question, heat pumps participate with small contribution in heat generation, i.e. biomass-based technologies have a dominant role and hence the consumption of primary energy is significantly larger.
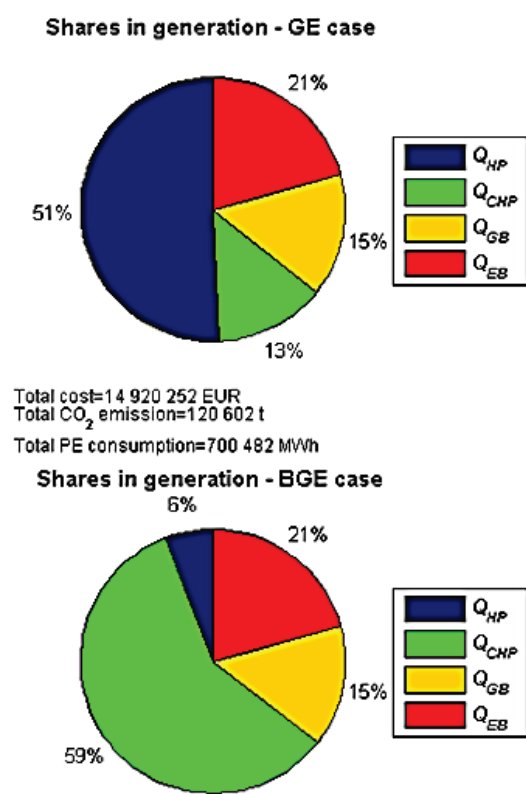

Total cost $=4501194$ EUR
Total $\mathrm{CO}_{2}$ emission $=84626$

Total PE consumption=1 $186743 \mathrm{MWh}$

Figure 16 Comparative analysis of different cases in the sense of shares of particular technology in heat generation, total yearly costs, total yearly $\mathrm{CO}_{2}$ emission and total yearly primary energy consumption

\section{DISCUSSION}

From the results obtained in this research, it is obvious that heat generation costs as well as selection of optimal generation set-up for heat generation are issues which should be addressed in the contemporary energy system.

Particularly, it is shown that EB is the most convenient technology for heat generation if the heat is needed sporadically, i.e. in very low number of hours per year. That conclusion is a consequence of a low investment cost into EB, low start up and shut down costs, as well as low maintenance costs. Therefore, EB technology is an acceptable solution if heat is needed at least 20 days during the year. It should also be asserted that GB have similar economic indicators as EB when heat generation costs are in question.

Heat pumps are the second-best technology in the sense of heat generation cost and required amount of time into operation. Namely, heat pumps can generate heat at even lower cost level than EB and GB due to the fact that their efficiencies are significantly greater than form the other observed technologies. However, when discussing heat pumps, it is necessary to mention their limitation i.e. potential obstacles which can occur during operation. If the 
heat source is not abundant enough or temperature level of heat source is too low, advantages of heat pumps are jeopardized. Therefore, when selecting heat pumps technology as the one for heat generation detailed analysis of potential heat source should be performed while adequate back-up technologies are also desirable.

Due to the cost of $\mathrm{CO}_{2}$ emissions cogeneration technologies of gas turbine and gas engine fuelled with natural gas are less competitive to the case when the mentioned cogeneration technologies are fuelled from biogas obtained from biomass gasification process. The economic indicators of cogeneration technologies fuelled by natural gas and the ones fuelled by biogas become comparable if heat is generated at full load for more than 180 days per year in the case of extremely high $\mathrm{CO}_{2}$ emission prices. If $\mathrm{CO}_{2}$ emission price is neglected then natural gas-based technologies are equally competitive as biogas-based technologies if operating entire year at nominal load.

\section{CONCLUSION}

Cogeneration technologies in the present design of energy systems were used as a large-scale unit, satisfying heat demands, while electricity production was treated as a by-product. Contemporary and future energy markets are more dynamic and conventional power plants, as well as cogeneration plants, will have to adapt in order to maintain their market share. On the other hand, ambitious goals of the EU regarding the climate change impose the need of deployment of technologies which are acceptable for society, mainly in the sense of $\mathrm{CO}_{2}$ emission. In that sense it is necessary to evaluate possible options for generation of heat and electricity in the socio-economic way.

This paper gives analyses regarding the cost of heat generation from combined cycle gas engine, gas engine, combined cycle gas turbine and gas engine propelled by the gas from wastewater sludge pellet gasification process, heat pump, electric and gas boiler. In order to obtain the heat price, different parameters, such as variable and fixed operation and maintenance costs, capital expenditures, $\mathrm{CO}_{2}$ emissions, were taken into consideration.

Heat pumps show the lowest cost of heat, while electric and gas boiler have advantage of relatively low required numbers of operational hours because of relatively low capital expenditures. Biomass-based technologies are competitive if they are operational more than 200 days per year. Gas-based cogeneration technologies generate heat at greatest costs and in that sense are not competitive. However, it is necessary to emphasize that within this research, benefits of gas engines and gas turbines, as flexible generation technologies which can participate in power system stabilisation, are neglected, i.e. they are neither economically nor technically evaluated.

Moreover, analysis was performed with data for the year 2012, due to their availability. In 2012 electricity prices were higher compared to year 2017 or 2018. This fact would certainly influence results, in the sense of economical efficiency of some technologies.

Results of three-criteria optimization procedures indicate that heat pump technology should be evaluated with more details, especially if compared to conventional generation technologies, such as gas turbine and gas engine. Heat pump generates approx. $50 \%$ of heat and thus reduces the number of operational hours of gas-based cogeneration technologies. On the other hand, biomassbased cogeneration technologies show significant reduction in costs compared to gas-based cogeneration technologies. However, the drawbacks of wastewater sludge utilized as an energy source are its accessibility (possible utilization on agricultural soils) and regulatory status (considered as a waste and not an energy source) and thus there is a question whether it is always possible to utilise wastewater sludge in large-scale biomass-based plants.

The mentioned benefits, such as possibilities to provide flexibility, i.e. ancillary services to the power system, and evaluation of the same is something that needs to be further addressed in the future research and what will give clearer picture of the most convenient choice of the heat and electricity generation technology in the future dynamic energy system.

\section{Acknowledgment}

Authors would like to express their gratitude to $\mathrm{Mr}$. Krešimir Komljenović, manager of the EL-TO power plant at HEP - Croatian national power utility company who put at disposal operational data which were essential for deployment of the optimisation procedure.

\section{Nomenclature}

$C^{z}$ - minimal cost of operation of generation set up during the $z$-th hour

$C_{\text {fuel,GB }}^{z}$ - cost of fuel for gas boiler during the $z$-th hour

$C_{\text {el. }}^{z}$ - price of electricity during the $z$-th hour

$C_{\text {heat }, i}$ - cost of heat generated by the $i$-th unit

$C_{\text {fuel,CHP }}^{z}$ cost of fuel for chosen cogeneration technology during the $z$-th hour

$C_{\text {fuel, } i}$ - cost of fuel of the $i$-th unit

$C_{\mathrm{CO} 2, i}$ - cost of $\mathrm{CO}_{2}$ emission of the $i$-th unit

$C_{\mathrm{VOM}, i}$ - variable cost of operation and maintenance of the $i$-th unit

$C_{\text {el. }}$ - cost of electricity

$C_{\text {Cap }, i}$ - investment cost of the $i$-th unit

$C_{\mathrm{FOM}, i}$ - fixed cost of operation and maintenance of the $i$ th unit

$C E_{\mathrm{opt}}^{z}$ - minimal $\mathrm{CO}_{2}$ emission for the $z$-th hours

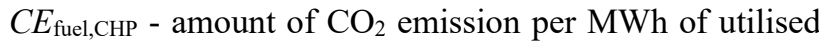
fuel for cogeneration technology

$C E_{\text {gas }}$ - amount of $\mathrm{CO}_{2}$ emission per $\mathrm{MWh}$ of utilised natural gas

$C E_{\text {el. }}$ - amount of $\mathrm{CO}_{2}$ emission per $\mathrm{MWh}$ of utilised electricity from the grid

$C R F$ - capital recovery factor

$i$ - index of technology

$P_{\mathrm{el} . \mathrm{HP}}^{z}$ - consumption of electricity of heat pump during the $z$-th hour

$P_{\text {el.,EB }}^{z}$ - consumption of electricity of electric boiler during the $z$-th hour 
$P_{\mathrm{el} ., \mathrm{CHP}}^{z}$ - generation of electricity by chosen cogeneration technology during the $z$-th hour

$P E U_{\mathrm{opt}}^{z}$ - minimal consumption of primary energy in the $z$ th hour

$P E F_{\text {fuel,CHP }}$ - primary energy factor for the fuel of the chosen cogeneration technology

$P E F_{\text {gas }}$ - primary energy factor for the natural gas

$P E F_{\text {el. }}$ - primary energy factor for the electricity from the grid

$\mathrm{PtH}_{i}$ - power-to-heat ratio of $i$-th unit

$Q_{\mathrm{h}, \mathrm{D}}-$ heat demand

$Q_{\mathrm{HP}}$ - heat generated by heat pump

$Q_{\text {CHP }}$ - heat generated by cogeneration unit

$Q_{\mathrm{GB}}$ - heat generated by gas boiler

$Q_{\text {EB }}$ - heat generated by electric boiler

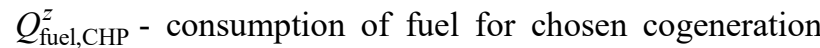
technology during the $z$-th hour

$Q_{\text {fuel,GB }}^{z}$ - consumption of fuel for gas boiler during the $z$-th hour

$z$ - hour in simulation

$\eta_{\mathrm{h}, i}$ - thermal efficiency of the $i$-th unit

$\eta_{\mathrm{e}, i}$ - electric efficiency of the $i$-th unit

\section{REFERENCES}

[1] European Commission. 2020 climate \& energy package, Retrieved from: http://ec.europa.eu/clima/policies/ strategies/2020/index en.htm.

[2] European Network of Transmission System Operators for Electricity. (2015). Electricity in Europe 2014. ENTSO-E.

[3] Batistella, L., Silva, V., Suzin, R., Virmond, E., Althoff, C., Moreira, R., \& José, H. (2015). Gaseous emissions from sewage sludge combustion in a moving bed combustor. Waste Management, 46, 430-439. https://doi.org/10.1016/..wasman.2015.08.039

[4] Späth, P. \& Rohracher, H. (2015). Conflicting strategies towards sustainable heating at an urban junction of heat infrastructure and building standards. Energy Policy, 78, 273-280. https://doi.org/10.1016/j.enpol.2014.12.019

[5] Webb, J. (2015). Improvising innovation in UK urban district heating: The convergence of social and environmental agendas in Aberdeen. Energy Policy, 78, 265272. https://doi.org/10.1016/j.enpol.2014.12.003

[6] Santoli, L., Mancini, F., Nastasi, B., \& Piergrossi, V. (2015). Building integrated bioenergy production (BIBP): Economic sustainability analysis of Bari airport CHP (combined heat and power) upgrade fueled with bioenergy from short chain. Renewable Energy, 81, 499-508. https://doi.org/10.1016/j.renene.2015.03.057

[7] Lund, R. \& Mathiesen, B. V. (2015). Large combined heat and power plants in sustainable energy systems. Applied Energy, 142, 389-395. https://doi.org/10.1016/j.apenergy.2015.01.013

[8] Connolly, D., Lund, H., \& Mathiesen, B.V. (2016). Smart Energy Europe: The technical and economic impact of one potential $100 \%$ renewable energy scenario for the European Union. Renewable and Sustainable Energy Reviews, 60, 1634-1653. https://doi.org/10.1016/j.rser.2016.02.025

[9] Bolton, R. \& Foxon, T. (2015). Infrastructure transformation as a socio-technical process - Implications for the governance of energy distribution networks in the UK. Technological Forecasting \& Social Change, 90, 538-550. https://doi.org/10.1016/j.techfore.2014.02.017
[10] Lund, H., Werner, S., Wiltshire, R., Svendsen, S., Thorsen, J., Hvelplund, F., \& Mathiesen, B. (2014). $4^{\text {th }}$ Generation District Heating (4GDH): Integrating smart thermal grids into future sustainable energy systems. Energy, 68, 1-11. https://doi.org/10.1016/j.energy.2014.02.089

[11] Serra, L., Lozano, M., Ramos, J., Ensinas, A., \& Nebra, S. (2009). Polygeneration and efficient use of natural resources. Energy, 34, 575-586. https://doi.org/10.1016/j.energy.2008.08.013

[12] Menon, R., Paolone, M., \& Maréchal, F. (2013). Study of optimal design of polygeneration systems in optimal control strategies. Energy, 55, 134-141. https://doi.org/10.1016/j.energy.2013.03.070

[13] Truong, N. \& Gustavsson, L. (2014). Minimum-cost district heat production systems of different sizes under different environmental and social cost scenarios. Applied Energy, 136, 881-893. https://doi.org/10.1016/j.apenergy.2014.07.080

[14] Rong, A. \& Lahdelma, R. (2005). An Efficient Linear Programming Model and Optimization Algorithm for Trigeneration. Applied Energy, 82, 40-63. https://doi.org/10.1016/j.apenergy.2004.07.013

[15] Gładysz, P. \& Ziębik, A. (2013). Complex analysis of the optimal coefficient of the share ocogeneration in district heating systems. Energy, 62, 12-22. https://doi.org/10.1016/j.energy.2013.04.032

[16] Wang, H., Yin, W., Abdollahi, E., Lahdelma, R., \& Jiao, W. (2015). Modelling and optimization of CHP based district heating system with renewable energy production and energy storage. Applied Energy, 159, 401-421. https://doi.org/10.1016/j.apenergy.2015.09.020

[17] Nuytten, T., Claessens, B., Paredis, K., Bael, J. V., \& Six, D. (2013). Flexibility of a combined heat and power system with thermal energy storage for district heating. Applied Energy, 104, 583-591. https://doi.org/10.1016/j.apenergy.2012.11.029

[18] Prato, A. P., Strobino, F., Broccardo, M., \& Giusino, L. P. (2012). Integrated management of cogeneration plants and district heating networks. Applied Energy, 97, 590-600. https://doi.org/10.1016/j.apenergy.2012.02.038

[19] Chicco, G. \& Mancarella, P. (2009). Matrix modelling of small-scale trigeneration systems and application to operational optimization. Energy, 34, 261-273. https://doi.org/10.1016/j.energy.2008.09.011

[20] Balić, D. \& Lončar, D. (2015). Impact of Fluctuating Energy Prices on the Operation Strategy of a Trigeneration System. Journal of Sustainable Development of Energy, Water and Environment Systems, 3, 315-332. https://doi.org/10.13044/j.sdewes.2015.03.0024

[21] Fracaro, G. P. M., Souza, S. N. M., Medeiros, M., Formentini, D. F., \& Marques, C. A. (2011). Economic feasibility of biomass gasification for small-scale electricity generation in Brazil. World Renewable Energy Congress, Sweden. https://doi.org/10.3384/ecp11057295

[22] Forsén, M. (2005). Heat Pumps - Technology and Environmental Impact, Part 1. Swedish Heat Pump Association, SVEP.

[23] Bierdel, T., Bullinger, P., \& Hagedorn, T. (2013). Life Cycle Value for combined cycle power plant. Siemens AG.

[24] European Commission. (2013). EU Energy, Transport and GHG Emissions Trends to 2050 - Reference Scenario 2013. EC.

[25] Croatian Ministry of Economy. (2014). Primary energy and $\mathrm{CO}_{2}$ emission factors.

[26] Murakami, T., Suzuki, Y., Nagasawa, H., Yamamoto, T., Koseki, T., Hirose, H., \& Okamoto, S. (2009). Combustion characteristics of sewage sludge in an incineration plant for energy recovery. Fuel Processing Technology, 90, 778-783. https://doi.org/10.1016/j.fuproc.2009.03.003 
[27] Lubinski, B. (2015). District Heating and Cooling + EPBD: Implementation via standardization. Euroheat \& Power Congress, Tallinn.

[28] European Commission. (2013).Best available technologies for the heat and cooling market in the European Union. Joint Research Centre and Institute for Energy and Transport.

[29] Lončar, D., Krajačić, G., \& Vujanović, M. (2009).Support to the developers - Best practices in biomass combined heat and power (CHP) in wood industry and forest sector. Knowledge and technology transfer centre: Croatian Bank for Reconstruction and Development, Zagreb.

[30] Hungarian Power Exchange. Available: www.hupx.hu/

[31] Danso, G., Otoo, M., Ekere, W., Ddungu, S., \& Madurangi, G. (2017). Market Feasibility of Faecal Sludge and Municipal Solid Waste-Based Compost as Measured by Farmers' Willingness-to-Pay for Product Attributes: Evidence from Kampala, Uganda. Resources, 6(31), 1-17. https://doi.org/10.3390/resources6030031

[32] Lue-Hing, C., Zenz, D. R., Tata, P., Kuchenrither, R., Malina, J. F., Jr., \& Sawyer, B. (1998). Municipal Sewage Sludge Management: A Reference Text on Processing, Utilization and Disposal, Second Edition - Volume 4. Basel, CRC Press.

\section{Contact information:}

Dinko ĐURĐEVIĆ, M .Env. Eng.

(Corresponding author)

Energy Institute Hrvoje Požar,

Savska cesta 163, 10000 Zagreb, Croatia

ddurdevic@eihp.h

Dražen BALIĆ, M. M. Eng.

Energy Institute Hrvoje Požar

Savska cesta 163, 10000 Zagreb, Croatia

dbalic@eihp.h

Željko JURIĆ, M. Sc. Mech. Eng.

Energy Institute Hrvoje Požar

Savska cesta 163, 10000 Zagreb, Croatia

zjuric@eihp.hr 